\title{
Investigations into Luminescent Properties of Sm(III), Eu(III), Tb(III) and Dy(III) Complexes of Some Schiff-base Ligands
}

\author{
Pawan Raj Shakya* and Chirika Shova Tamrakar \\ Department of Chemistry, Padma Kanya Multiple Campus \\ Tribhuvan University, Bagbazar, Kathmandu, Nepal. \\ *E-mail: pawansh2003@yahoo.com
}

\begin{abstract}
Luminescent properties of Sm(III), Eu(III), Tb(III) and Dy(III) complexes of three Schiff-base ligands viz., $\mathrm{H}_{2} \mathrm{~L}^{1}, \mathrm{H}_{2} \mathrm{~L}^{2}$ and $\mathrm{H}_{2} \mathrm{~L}^{3}$ [where $\mathrm{H}_{2} \mathrm{~L}^{1}=N, N^{\prime}$-di-(4-decyloxysalicylidene)-1', 4'-diaminobutane; $\mathrm{H}_{2} \mathrm{~L}^{2}=N, N^{\prime}$-di-(4-decyloxysalicylidene)2',6'-diaminopyridine; and $\mathrm{H}_{2} \mathrm{~L}^{3}=N, N^{\prime}$-di-(4-decyloxysalicylidene)-1',3'-diaminobenzene] synthesized in our earlier work were investigated. The homo dinuclear lanthanide complexes were of the type, $\left[\mathrm{Ln}_{2}\left(\mathrm{LH}_{2}\right)_{3}\left(\mathrm{NO}_{3}\right)_{4}\right]\left(\mathrm{NO}_{3}\right)_{2}$. Luminescence analysis revealed that among the lanthanide complexes, only $\mathrm{Sm}$ (III) complex of $\mathrm{H}_{2} \mathrm{~L}^{1}$ was found to have displayed characteristic metal-centered emission (solution state) whereas $\mathrm{Sm}(\mathrm{III}), \mathrm{Eu}(\mathrm{III})$ and $\mathrm{Tb}$ (III) complexes of $\mathrm{H}_{2} \mathrm{~L}^{2}$ and $\mathrm{Eu}(\mathrm{III})$ and $\mathrm{Tb}(\mathrm{III})$ complexes of $\mathrm{H}_{2} \mathrm{~L}^{3}$ exhibited ligand-centered emissions.
\end{abstract}

Key word: Ln(III) complexes, Luminescence, Schiff-base ligands, metal/ligand centered emissions

\section{INTRODUCTION}

Synthesis of luminescent lanthanide complexes has been of considerable interest because of their potential applications, such as fluorescent labeling reagents, imaging agents, and emitter materials in organic lightemitting diodes (OLEDs) (Diaz-Garcia et al. 2002; Frias et al. 2003; Bunzli \& Piguet, 2005). Generally, complexes of $\mathrm{Eu}^{3+}, \mathrm{Sm}^{3+}, \mathrm{Tb}^{3+}$, and $\mathrm{Dy}^{3+}$ are considered to have the brightest emission, but the luminescence efficiency of these complexes largely depends on the choice of organic ligands (Crosby et al. 1962). Since the forbidden $f-f$ transitions make direct photoexcitation of lanthanide ions unfavored, the organic ligands function like an antenna by absorbing light and transferring this energy to the excited states of the central lanthanide ion. The excited lanthanide ion then undergoes radiative transitions to lower energy states resulting in characteristic multiple narrowband emissions. The commonly accepted mechanism of energy transfer from the organic ligand to the lanthanide ion is that of Crosby and Whan (Bunzli \& Eliseeva, 2009) and generally occurs in three steps: (i) light harvesting by the host or ligands, (ii) energy transfer onto the metal ion, and (iii) metal-centered emission. A simplified scheme of these energy transfers is given in Fig. 1. The overall process is quite complex and involves several mechanisms and energy levels. Since the intensity of the emission (brightness) and choice of lanthanide (i.e., color of emission) both depend on the sensitizer, new sensitizing chromophores are highly sought after (Pope et al. 2004). Several nitrogen- and oxygen-donor ligands have been utilized in the sensitization of lanthanide luminescence (Cui et al. 2007; Zhou et al. 2008).



Fig. 1. Simplified diagram showing the main energy flow paths during sensitization of lanthanide luminescence via its surroundings (ligands) (Source: Bunzli \& Eliseeva, 2009).

More recently, we performed a systematic study on lanthanide complexes consisting of the mesogenic Schiffbase ligands and we found an overall stoichiometry $\left[\mathrm{Ln}_{2}\left(\mathrm{LH}_{2}\right)_{3}\left(\mathrm{NO}_{3}\right)_{4}\right]\left(\mathrm{NO}_{3}\right)_{2}$ for all the complexes (Shakya et al. 2012a, 2012b, 2014). In continuation of our earlier work, a study on room temperature luminescent properties of the complexes of some $\mathrm{Ln}(\mathrm{III})$ ions $(\mathrm{Ln}=\mathrm{Sm}, \mathrm{Eu}, \mathrm{Tb}$ and Dy) is reported in this paper. The effect of varying the neutral bi-dentate ligands on the luminescence behaviour of these complexes is investigated. 


\section{MATERIALS AND METHODS}

\section{General Information}

All operations were performed in an open atmosphere. The Schiff-base ligands (Fig. 2) viz., N,N'-di-(4decyloxysalicylidene)-1', 4'-diaminobutane $\quad\left(\mathrm{H}_{2} \mathrm{~L}^{1}\right)$, $N, N$ '-di-(4-decyloxysalicylidene)-2',6'-diaminopyridine $\left(\mathrm{H}_{2} \mathrm{~L}^{2}\right)$ and $N, N^{\prime}$-di-(4-decyloxysalicylidene)-1',3'diaminobenzene $\left(\mathrm{H}_{2} \mathrm{~L}^{3}\right)$ were prepared by condensation of 4-decyloxysalicylaldehyde with different spacers such as 1,4-diaminobutane, 2,6-diaminopyridine and 1,3-diaminobenzene in absolute ethanol in presence of acetic acid as reported in our earlier work (Shakya et al. 2012a, 2012b \& 2014). $\mathrm{Ln}\left(\mathrm{NO}_{3}\right)_{3} \cdot 6 \mathrm{H}_{2} \mathrm{O}(\mathrm{Ln}=$ $\mathrm{Sm}, \mathrm{Eu}, \mathrm{Tb}$ and $\mathrm{Dy})$ were prepared by reactions of lanthanide oxide and nitric acid. All other chemicals were used as purchased. Infrared spectra were recorded on a JASCO FT/IR (model-5300) spectrophotometer in the $4000-400 \mathrm{~cm}^{-1}$ region using $\mathrm{KBr}$ pellets. Elemental $(\mathrm{C}, \mathrm{H}$, and $\mathrm{N})$ analyses were performed on an Exeter Analyzer, Model CE-440 CHN. The metal contents of the complexes were determined by complexometric titrations against EDTA using xylenol orange as an indicator. Magnetic susceptibility measurements were made at room temperature on a Cahn-Faraday balance using $\mathrm{Hg}\left[\mathrm{Co}(\mathrm{NCS})_{4}\right]$ as the calibrant. Luminescence measurements were made in solution state (mixed solvent of $\mathrm{CHCl}_{3} / \mathrm{DMSO} ; 3: 1, \mathrm{v} / \mathrm{v}$ ) on a Perkin Elmer LS-45 luminescence spectrometer with a $10 \mathrm{~nm}$ slit width on both excitation and emission.

\section{Synthesis of Ln(III) complexes}

All complexes (Fig. 2) were synthesized by direct addition of the hydrated lanthanide nitrate $\mathrm{Ln}(\mathrm{NO})_{3}$. $\mathrm{xH}_{2} \mathrm{O}(\mathrm{Ln}=\mathrm{Sm}, \mathrm{Eu}, \mathrm{Tb}$ and Dy) in THF solution to a stirred THF solution of the Schiff-base ligands viz., $\mathrm{H}_{2} \mathrm{~L}^{1}$, $\mathrm{H}_{2} \mathrm{~L}^{2}$ and $\mathrm{H}_{2} \mathrm{~L}^{3}$ as reported in our earlier work (Shakya et al. 2012a, 2012b \& 2014). For instance, a solution of $\mathrm{Sm}\left(\mathrm{NO}_{3}\right)_{3} \cdot 6 \mathrm{H}_{2} \mathrm{O}(0.89 \mathrm{~g}, 2.0 \mathrm{mmol}$ in $20 \mathrm{~mL})$ in THF was added dropwise to a stirred THF solution of the ligand, $\mathrm{H}_{2} \mathrm{~L}^{1}(1.83 \mathrm{~g}, 3.0 \mathrm{mmol}$ in $30 \mathrm{~mL})$. After addition, the solution was left under magnetic stirring for $\sim 3 \mathrm{~h}$ at room temperature when a light yellow solid product separated out which was filtered, washed repeatedly with cold methanol and dried over fused $\mathrm{CaCl}_{2}$. Yield: $70 \%(1.75 \mathrm{~g})$. Elemental analysis calculated for $\mathrm{Sm}_{2} \mathrm{C}_{114} \mathrm{H}_{180} \mathrm{~N}_{12} \mathrm{O}_{30}(M w$ $=2499.43)$ : C, 54.78\%; H, 7.26\%; and N, 6.72\%; found: C, $54.74 \%$; H, $7.28 \%$; and $\mathrm{N}, 6.74 \%$.

All the other complexes of Eu(III), Tb(III) and Dy(III) ions were obtained via the same synthetic method as described above.
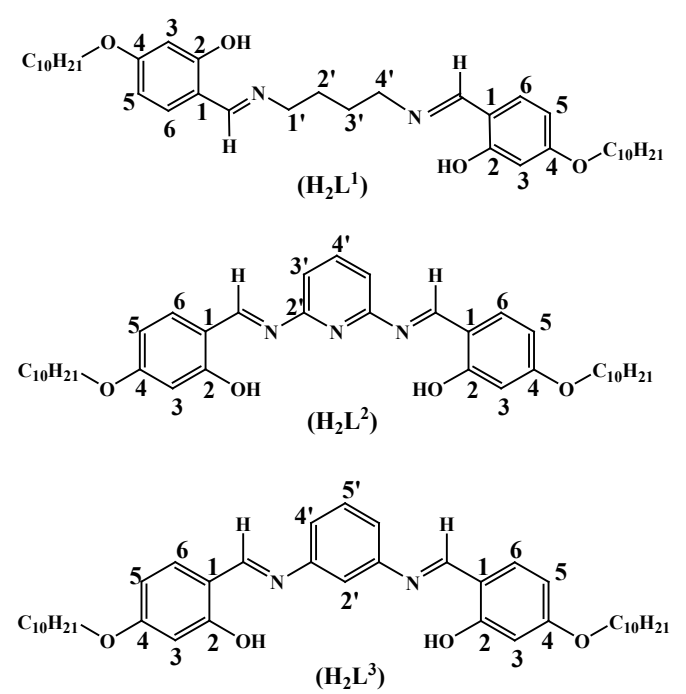

$3 \mathrm{H}_{2} \mathrm{~L}^{\mathrm{n}}+2 \mathrm{Ln}\left(\mathrm{NO}_{3}\right)_{3} \cdot \mathrm{xH}_{2} \mathrm{O} \underset{\text { Stir \& reflux, } \sim 3 \mathrm{~h} .}{\stackrel{\mathrm{THF}}{\longrightarrow}}\left[\operatorname{Ln}_{2}\left(\mathrm{~L}^{\mathrm{n}} \mathrm{H}_{2}\right)_{3}\left(\mathrm{NO}_{3}\right)_{4}\right]\left(\mathrm{NO}_{3}\right)_{2}+\mathrm{xH}_{2} \mathrm{O}$

Where,

$\mathrm{n}=1,2$ or 3

Ln $=$ Sm, Eu, Tb and Dy

Fig. 2. Schiff-base ligands and Ln(III) complexes discussed in this paper.

\section{RESULTS AND DISCUSSION}

Nature of the Sm(III), Eu(III), Tb(III) and Dy(III) complexes

The Schiff-base ligands viz., $\mathrm{H}_{2} \mathrm{~L}^{1}, \mathrm{H}_{2} \mathrm{~L}^{2}$ and $\mathrm{H}_{2} \mathrm{~L}^{3}$ were obtained by condensing 4-decyloxysalicyldehyde with different spacers such as 1,4-diaminobutane, 2,6-diaminopyridine and 1,3-diaminobenzene (Fig. 2). Reaction of excess $\mathrm{Ln}(\mathrm{NO})_{3} \cdot \mathrm{xH}_{2} \mathrm{O}$ with the Schiff-base ligands in absolute ethanol then led to the formation of the complexes with the general formula, $\left[\mathrm{Ln}_{2}\left(\mathrm{LH}_{2}\right)_{3}\left(\mathrm{NO}_{3}\right)_{4}\right]$ $\left(\mathrm{NO}_{3}\right)_{2}$ indicating 2:3 metal to ligand stoichiometry. The nitrate groups were found to be present both within as well as outside the coordination sphere; the number of the ionic species was implied by the molar conductance data showing 2:1 electrolytic behavior. Besides, it has been shown earlier by IR and NMR studies that in each case of the nitrate complexes, coordination occurs through the phenol oxygen only, the ligand being present in a zwitterionic form. The four nitrate counter-ions coordinate in a bidentate fashion, bringing the coordination number of the lanthanide ion to seven and the polyhedron being possibly distorted mono-capped octahedron.

\section{Luminescent properties of the complexes}

Luminescent emission spectra (with the excitation and emission slit widths of $10.0 \mathrm{~nm}$ ) of the $\mathrm{Sm}(\mathrm{III}), \mathrm{Eu}(\mathrm{III})$, $\mathrm{Tb}$ (III) and Dy(III) complexes of the Schiff-base ligands, viz., $\mathrm{H}_{2} \mathrm{~L}^{1}, \mathrm{H}_{2} \mathrm{~L}^{2}$, and $\mathrm{H}_{2} \mathrm{~L}^{3}$ in a mixed solvent of $\mathrm{CHCl}_{3} /$ 
$\operatorname{DMSO}\left(3: 1, \mathrm{v} / \mathrm{v} ; 1.0 \times 10^{-4} \mathrm{~mol} \mathrm{~L}^{-1}\right)$ were recorded at medium PMT voltage. Under identical experimental conditions, the luminescent characteristics of all the above complexes under discussion are listed in Table 1 while the corresponding spectra of the same are shown in Figs. 3-5.

Table 1. Luminescence data of the complexes

\begin{tabular}{|c|c|c|c|c|c|c|}
\hline $\begin{array}{c}\text { S. } \\
\text { No. }\end{array}$ & Complexes & $\begin{array}{c}\text { Slit width } \\
\text { (nm) }\end{array}$ & $\lambda_{\mathrm{ex}}(\mathrm{nm})$ & $\begin{array}{c}\lambda_{\mathrm{em}} \\
(\mathrm{nm})\end{array}$ & ${ }^{\mathrm{a}} \mathbf{F I}$ & Assignment \\
\hline 1. & {$\left[\mathrm{Sm}_{2}\left(\mathrm{~L}^{1} \mathrm{H}_{2}\right)_{3}\left(\mathrm{NO}_{3}\right)_{4}\right]\left(\mathrm{NO}_{3}\right)_{2}$} & 10 & 386 & $\begin{array}{l}468,560 \\
598,644\end{array}$ & $\begin{array}{c}28,10 \\
12,7\end{array}$ & $\begin{aligned} \pi & -\pi^{*}, \\
{ }^{4} G_{5 / 2} & \rightarrow{ }^{6} H_{5 / 2}, \\
{ }^{4} G_{5 / 2} & \rightarrow{ }^{6} H_{7 / 2}, \\
{ }^{4} G_{5 / 2} & \rightarrow{ }^{6} H_{9 / 2}\end{aligned}$ \\
\hline 2. & {$\left[\mathrm{Eu}_{2}\left(\mathrm{~L}^{1} \mathrm{H}_{2}\right)_{3}\left(\mathrm{NO}_{3}\right)_{4}\right]\left(\mathrm{NO}_{3}\right)_{2}$} & 10 & 380 & 441 & $<2$ & - \\
\hline 3. & {$\left[\mathrm{~Tb}_{2}\left(\mathrm{~L}^{1} \mathrm{H}_{2}\right)_{3}\left(\mathrm{NO}_{3}\right)_{4}\right]\left(\mathrm{NO}_{3}\right)_{2}$} & 10 & 380 & 438 & $<2$ & - \\
\hline 4. & {$\left[\mathrm{Dy}_{2}\left(\mathrm{~L}^{1} \mathrm{H}_{2}\right)_{3}\left(\mathrm{NO}_{3}\right)_{4}\right]\left(\mathrm{NO}_{3}\right)_{2}$} & 10 & 369 & 426 & $\sim 2.5$ & - \\
\hline 5. & {$\left[\mathrm{Sm}_{2}\left(\mathrm{~L}^{2} \mathrm{H}_{2}\right)_{3}\left(\mathrm{NO}_{3}\right)_{4}\right]\left(\mathrm{NO}_{3}\right)_{2}$} & 10 & 380 & 436 & $<14$ & $\pi-\pi^{*}$ \\
\hline 6. & {$\left[\mathrm{Eu}_{2}\left(\mathrm{~L}^{2} \mathrm{H}_{2}\right)_{3}\left(\mathrm{NO}_{3}\right)_{4}\right]\left(\mathrm{NO}_{3}\right)_{2}$} & 10 & 383 & 487 & 8 & $\pi-\pi^{*}$ \\
\hline 7. & {$\left[\mathrm{~Tb}_{2}\left(\mathrm{~L}^{2} \mathrm{H}_{2}\right)_{3}\left(\mathrm{NO}_{3}\right)_{4}\right]\left(\mathrm{NO}_{3}\right)_{2}$} & 10 & 382 & 457 & 128 & $\pi-\pi^{*}$ \\
\hline 8. & {$\left[\mathrm{Dy}_{2}\left(\mathrm{~L}^{2} \mathrm{H}_{2}\right)_{3}\left(\mathrm{NO}_{3}\right)_{4}\right]\left(\mathrm{NO}_{3}\right)_{2}$} & 10 & 384 & 495 & $<1$ & - \\
\hline 9. & {$\left[\mathrm{Sm}_{2}\left(\mathrm{~L}^{3} \mathrm{H}_{2}\right)_{3}\left(\mathrm{NO}_{3}\right)_{4}\right]\left(\mathrm{NO}_{3}\right)_{2}$} & 10 & 348 & - & - & - \\
\hline 10. & {$\left[\mathrm{Eu}_{2}\left(\mathrm{~L}^{3} \mathrm{H}_{2}\right)_{3}\left(\mathrm{NO}_{3}\right)_{4}\right]\left(\mathrm{NO}_{3}\right)_{2}$} & 10 & 348 & 460 & 103 & $\pi-\pi^{*}$ \\
\hline 11. & {$\left[\mathrm{~Tb}_{2}\left(\mathrm{~L}^{3} \mathrm{H}_{2}\right)_{3}\left(\mathrm{NO}_{3}\right)_{4}\right]\left(\mathrm{NO}_{3}\right)_{2}$} & 10 & 347 & 515 & 4 & $\pi-\pi^{*}$ \\
\hline 12. & {$\left[\mathrm{Dy}_{2}\left(\mathrm{~L}^{3} \mathrm{H}_{2}\right)_{3}\left(\mathrm{NO}_{3}\right)_{4}\right]\left(\mathrm{NO}_{3}\right)_{2}$} & 10 & 348 & 419 & $<1$ & - \\
\hline
\end{tabular}
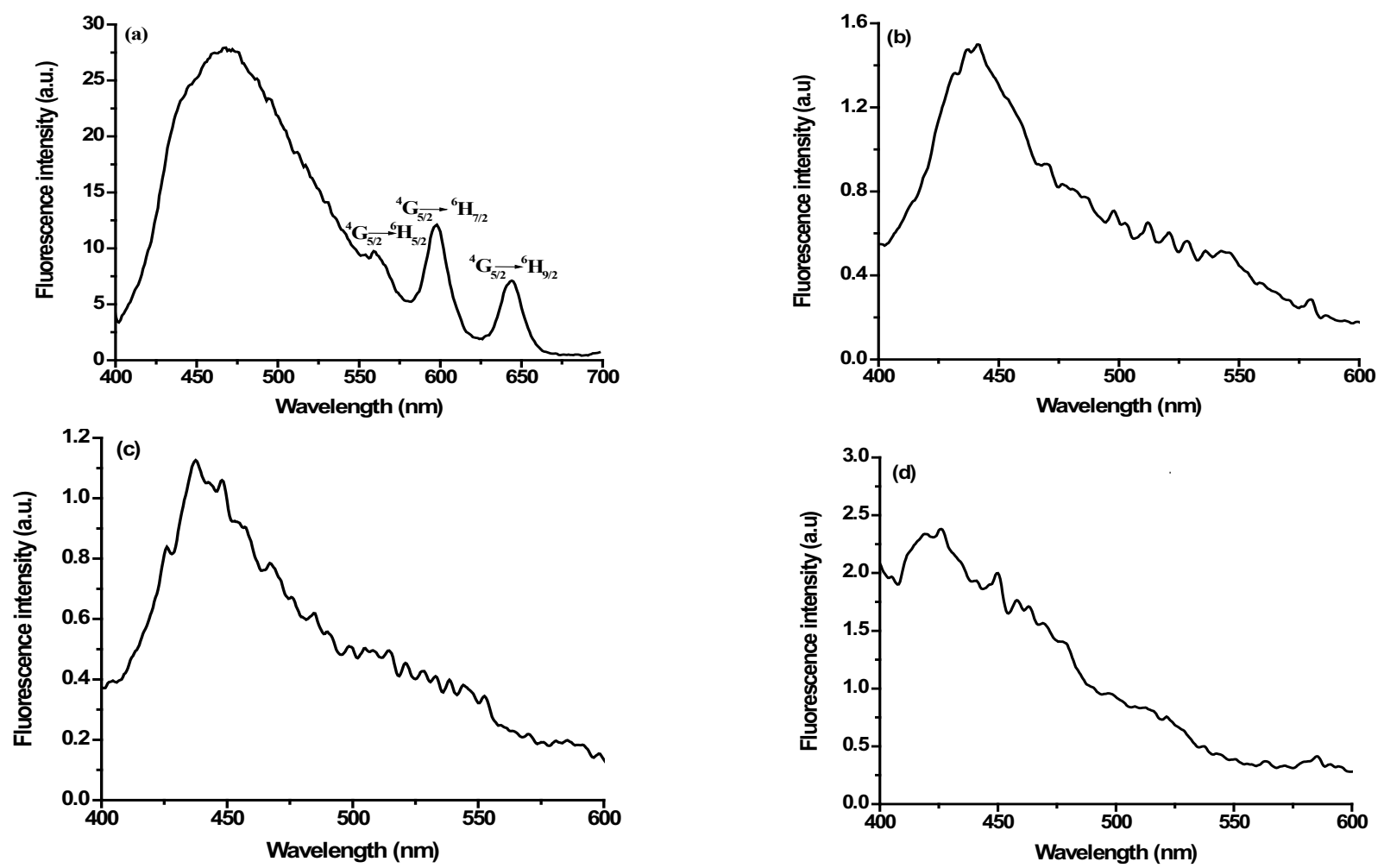

Fig. 3. Luminescent emission spectra of (a) $\mathrm{Sm}^{\mathrm{III}}$, (b) $\mathrm{Eu}^{\mathrm{III}}$, (c) $\mathrm{Tb}^{\mathrm{III}}$ and (d) $\mathrm{Dy}^{\mathrm{III}}$ complexes of $\mathrm{H}_{2} \mathrm{~L}^{1}$. 
Among the complexes of $\mathrm{H}_{2} \mathrm{~L}^{1}$ studied, none of the complexes except Sm(III) under present discussion exhibits spectral bands characteristic of metal-centered emission [Fig. 3(a-d)]. The excitation of the Sm(III) complex at $386 \mathrm{~nm}$ leads to emission of $\mathrm{Sm}^{3+}$ with four typical emission bands [Fig. 3 (a)] at 468, 560, 598 and $644 \mathrm{~nm}$ due to $\pi-\pi^{*}$ transitions of the ligand and ${ }^{4} \mathrm{G}_{5 / 2}$ $\rightarrow{ }^{6} \mathrm{H}_{\mathrm{J}}(J=5 / 2,7 / 2,9 / 2)$ transitions (An et al. 2004, Yan et al. 2007). The ligand retains its emission at a shorter wavelength. Some absorbed energy was transferred to the central Sm(III) ions, emitting characteristic fluorescence of the $\mathrm{Sm}^{3+}$ ion. Among the emission bands, the band around $598 \mathrm{~nm}$ is attributed to the hypersensitive ${ }^{4} \mathrm{G}_{5 / 2}$ $\rightarrow{ }^{6} \mathrm{H}_{7 / 2}$ transition in accordance with those already reported for some samarium coordination polymers (An et al. 2004; Song \& Yan, 2005). The fluorescence of the $\mathrm{Sm}$ (III) complex indicates that the energy level of the triplet state of the ligand, $\mathrm{H}_{2} \mathrm{~L}^{1}$ corresponded to the lowest excited state $\left({ }^{4} \mathrm{G}_{5 / 2}\right)$ level of $\mathrm{Sm}^{3+}$ ion. Apparently, one of the metal centered bands $(560 \mathrm{~nm})$ is found to be partially
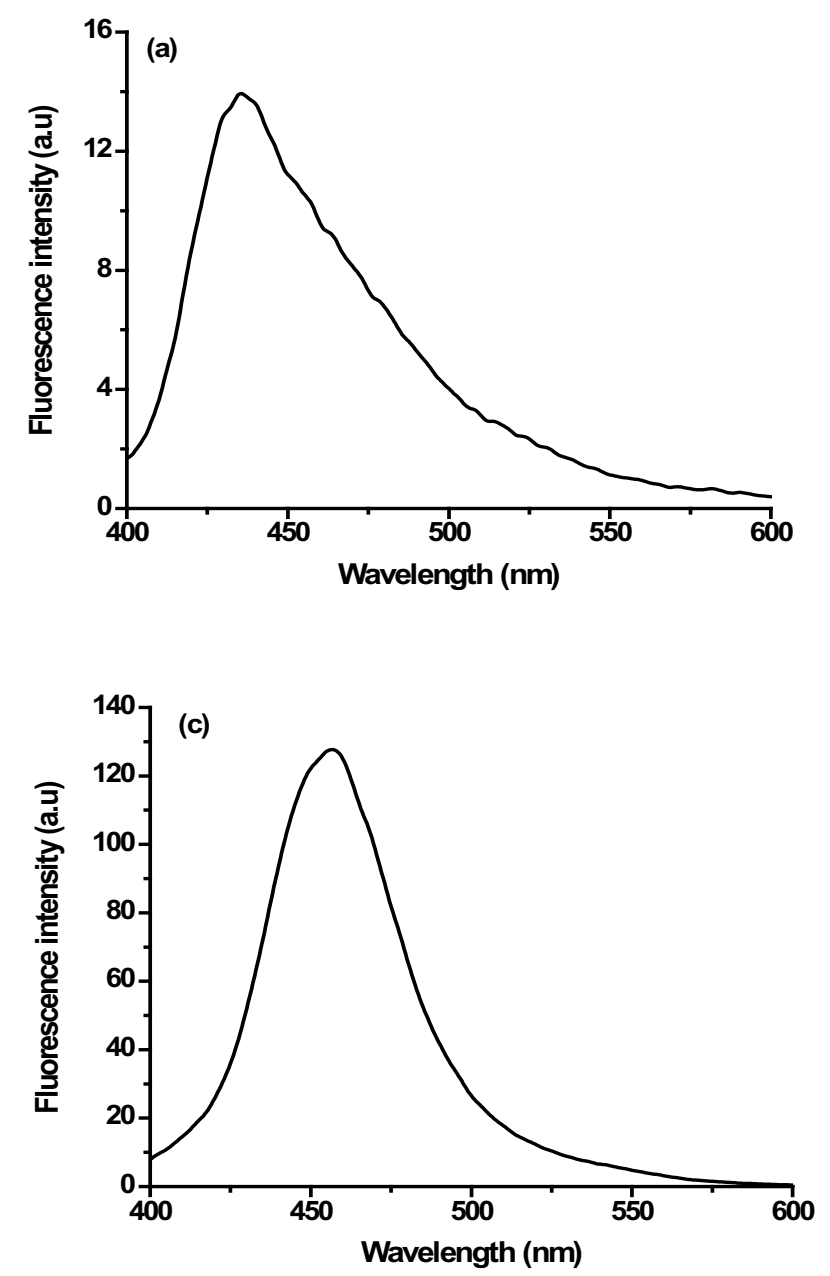

overlapped with the broad band of ligand emission. The $\mathrm{Eu}(\mathrm{III}), \mathrm{Tb}(\mathrm{III})$ and $\mathrm{Dy}(\mathrm{III})$ complexes exhibit very weak emissions and hence may be considered to be nonfluorescent in behaviour.

All the complexes of $\mathrm{H}_{2} \mathrm{~L}^{2}$ are devoid of any spectral bands characteristic of metal-centered emission [Fig. 4(a-d)]. However, a broad emission band at $436 \mathrm{~nm}$ (excitation energy, $\lambda_{\text {ex }}$ of $380 \mathrm{~nm}$ ) observed in the Sm(III) complex [Fig. 4(a)] may be attributed to ligand-centered emission (Shi et al. 2009). Similarly, the Eu(III) complex also exhibits a non metal-centered broad emission [Fig. 4(b)] at $487 \mathrm{~nm}$ when excited at $383 \mathrm{~nm}$, probably because of ligand emission (Zhang et al. 2009). Besides, an emission band with a relative fluorescence intensity of 124a.u. appearing at $457 \mathrm{~nm}$ (excitation energy, $\lambda_{\mathrm{ex}}$ of $382 \mathrm{~nm}$ ) in the spectrum of Tb(III) complex [Fig. 4(c)] may be attributed to the ligand-centered emission (Yang \& Wong, 2001). The Dy(III) complex is found to be nonfluorescent.


Fig. 4. Luminescent emission spectra of (a) $\mathrm{Sm}^{\mathrm{III}}$, (b) $\mathrm{Eu}^{\mathrm{III}}$, (c) $\mathrm{Tb}^{\mathrm{III}}$ and (d) $\mathrm{Dy}^{\mathrm{III}}$ complexes of $\mathrm{H}_{2} \mathrm{~L}^{2}$. 

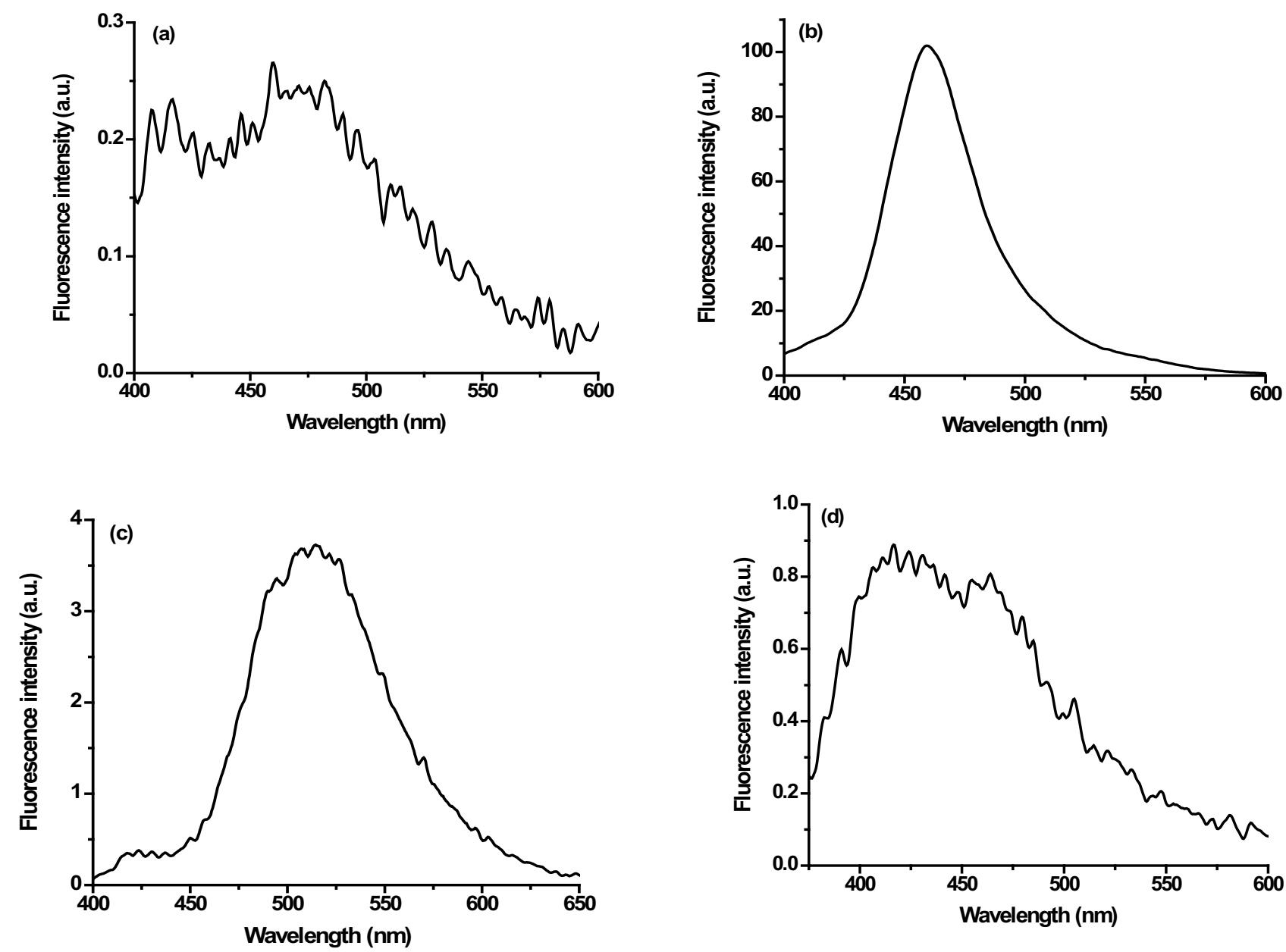

Fig. 5. Luminescent emission spectra of (a) $\mathrm{Sm}^{\mathrm{III}}$,

Among the metal complexes of $\mathrm{H}_{2} \mathrm{~L}^{3}$, the $\mathrm{Eu}$ (III) and $\mathrm{Tb}$ (III) complexes show broad emission bands respectively at $460 \mathrm{~nm}$ (excitation energy, $\lambda_{\text {ex }}$ of 348 $\mathrm{nm}$ ) and $515 \mathrm{~nm}$ (excitation energy, $\lambda_{\text {ex }}$ of $347 \mathrm{~nm}$ ) [Fig. 5(b\&.c)]. However, both the emissions are non-metal centered and hence may be attributed to emissions from their respective ligands (Zhang et al. 2009, Yang \& Wong, 2001). The Sm(III) and Dy(III) complexes [Fig. 5 (a\&.d)] may be considered to be non-fluorescent.

\section{CONCLUSION}

Due to the inherently weak luminescence of lanthanides, sensitization of their luminescence by organic ligands has been widely investigated. In this paper, the room temperature luminescence behaviour of $\mathrm{Sm}(\mathrm{III}), \mathrm{Eu}(\mathrm{III})$, $\mathrm{Tb}(\mathrm{III})$ and $\mathrm{Dy}(\mathrm{III})$ complexes of the Schiff-base ligands $\mathrm{H}_{2} \mathrm{~L}^{1}, \mathrm{H}_{2} \mathrm{~L}^{2}$ and $\mathrm{H}_{2} \mathrm{~L}^{3}$ is reported. Among the metal complexes under investigation, the characteristic metal-centered luminescence (solution state) has been observed on complexation of $\mathrm{H}_{2} \mathrm{~L}^{1}$ with $\mathrm{Sm}$ (III) ion only whereas $\mathrm{Sm}(\mathrm{III}), \mathrm{Eu}(\mathrm{III})$ and $\mathrm{Tb}(\mathrm{III})$ complexes of $\mathrm{H}_{2} \mathrm{~L}^{2}$ and $\mathrm{Eu}(\mathrm{III})$ and $\mathrm{Tb}(\mathrm{III})$ complexes of $\mathrm{H}_{2} \mathrm{~L}^{3}$ show ligandcentered emissions. Thus, it may be inferred that the ligand, $\mathrm{H}_{2} \mathrm{~L}^{1}$ is likely to be a suitable organic chelator to absorb energy and transfer the same to Sm(III) ion. The suitability of the energy gap between the lowest excited ligand-localized triplet state and the metal-centered emissive states is a critical factor for the sensitization of lanthanide luminescence. Moreover, the molecular structure of the ligand should also be considered in designing highly emissive lanthanide complexes

\section{ACKNOWLEDGEMENTS}

We are very much grateful to Prof. L. Mishra, Department of Chemistry, Banaras Hindu University, Varanasi for providing laboratory facility for luminescence measurements. 


\section{REFERENCES}

An, B.L., Gong, M.L., Li, M.X. and Zhang, J.M. 2004. Synthesis, structure and luminescence properties of samarium (III) and dysprosium (III) complexes with a new tridentate organic ligand. Journal of Molecular Structure 687: 1-6.

Bunzli, J.C.G and Eliseeva, S.V. 2009. Basics of Lanthanide Photophysics. In Lanthanide Spectroscopy, Materials and Bio-Applications, Hanninen, P. and Harma, H., Eds. Springer: Vol. 7.

Bunzli, J.C.G. and Piguet, C. 2005. Taking advantage of luminescent lanthanide ions. Chemical Society Reviews 34: 1048-1077.

Crosby, G.A., Whan, R.E. and Freeman, J.J. 1962. Spectroscopic studies of rare earth chelates. Journal of Physical Chemistry 66: 2493-2499.

Cui, H.X., Chen, J.M. and Zhou, H.D. 2007. Synthesis and fluorescent properties of $\mathrm{Eu}$ and $\mathrm{Tb}$ complexes with a series of new diamide ligands. Inorganic Chemistry Communications 10: 772-775.

Diaz-Garcia, M.A., De Avila, S.F. and Kuzyk, M.G. 2002. Dye-doped polymers for blue organic diode lasers. Applied Physics Letters 81: 3924-3926.

Frias, J.C., Bobba, G., Cann, M.J., Hutchinson, C.J. and Parker, D. 2003. Luminescent nonacoordinate cationic lanthanide complexes as potential cellular imaging and reactive probes. Organic Biomolecular Chemistry 1: 905-907.

Pope, S., Coe, B.J., Faulkner, S., Bichenkova, E.V., Yu, X. and Douglas, K.T. 2004. Self-Assembly of Heterobimetallic d-f Hybrid Complexes: Sensitization of Lanthanide Luminescence by d-Block Metal-to-Ligand Charge-Transfer Excited States. Journal of American Chemical Society 126: 9490-9491.

Shakya, P.R., Singh, A.K. and Rao, T.R. 2012a. Synthesis and characterization of lanthanide(III) complexes with a mesogenic Schiff-base, $N, N^{\prime}$-di(4-decyloxysalicylidene)-2',6'-diaminopyridine. Materials Science and Engineering C 32: 19061911.
Shakya, P.R., Singh, A.K. and Rao, T.R. 2012b. Complexes of some $4 f$ metal ions of the mesogenic Schiff-base, $N, N^{\prime}$-di-(4-decyloxysalicylidene)-1',3'diaminobenzene: synthesis and spectral studies. Journal of Coordination Chemistry 65: 3519-3529.

Shakya, P.R., Singh, A.K. and Rao, T.R. 2014. Rare Earth Metal Complexes of a Mesogenic Schiff-Base, $N, N^{\prime}$ di-(4-decyloxysalicylidene)-1',4'-diaminobutane: Synthesis and Characterization. Synthesis and Reactivity in Inorganic, Metal-Organic and NanoMetal Chemistry 44: 739-747.

Shi, X.M., Tang, R.R., Gu, G.L. and Huang, K. 2009. Synthesis and fluorescence properties of lanthanide(III) complexes of a novel bis(pyrazolylcarboxyl)pyridine-based ligand. Spectrochimica Acta A 72: 198-203.

Song, Y.S. and Yan, B. 2005. A novel unexpected luminescent quarternary coordination polymer $\left\{\mathrm{Sm}^{3}(\mathrm{C} 8 \mathrm{H} 4 \mathrm{O} 4) 4(\mathrm{C} 12 \mathrm{~N} 2 \mathrm{H} 8) 2(\mathrm{NO} 3)\right\} n$ with three high asymmetrical central $\mathrm{Sm}$ fragments by hydrothermal assembly. Inorganic Chimica Acta 358: 191-195.

Yan, P., Sun, W., Li, G., Nie, C., Gao, T. and Yue, Z. 2007. Synthesis, characterization and fluorescence studies of lanthanide Schiff-base complexes. Journal of Coordination Chemistry 60: 19731982.

Yang, C. and Wong, W.T. 2001. Synthesis and chromic luminescent properties of terbium(III) complexes with novel octopus carboxylates. Journal of Materials Chemistry 11: 2898-2900.

Zhang, L., Jiang, F. and Zhou, Y. 2009. Structures and fluorescence of two new hetero dinuclear lanthanide(III) complexes derived from a Schiffbase ligand. Journal of Coordination Chemistry 62: 1476-1483.

Zhou, Y.X., Shen, X.Q., Zhang, H.Y., Du, C.X., Wu, B.L. and Hou, H.W. 2008. Crystal structures and luminescence properties of two new terbium complexes with aromatic carboxylic acid. Journal of Coordination Chemistry 61: 3981-3992. 